\title{
Birthing and Family Medicine: More Than Obstetrics
}

Osman Sanyer, $M D$

The term birth injury usually applies to an injury sustained by either a woman or her infant in the course of giving birth. In this case the injury was sustained by the delivering family physician. What initially seemed like a minor injury turned out to require a significant career modification. The writer reflects on the personal impact of his choice to provide maternity care as a family physician. The unexpected end to this part of his practice, brought on by the injury, allows an opportunity to assess the effect of other "birth" experiences that are inherent to long-term patient-doctor relationships in family medicine. (J Am Board Fam Med 2015;28:535-536.)

\section{Keywords: Career Choice, Obstetrics}

"Is everything OK?" The laboring mother's gasped question silences the delivery room. The resident turns to catch my eye with that look-the one of anxious uncertainty. After 30 years of providing maternity care as a family physician, I have learned that this alarmed glance, an unusual quiet at the end of a delivery, means that something is not going as expected. I step forward and take over the delivery.

In most instances, a shoulder dystocia can be relieved with a few simple maneuvers. This time, it does not go easily. As the infant's shoulders finally begin to rotate from a firmly wedged malposition in the mother's pelvis, I feel a sharp pop in the knuckles of my right hand. The pain is startling but tolerable, and is quickly forgotten as the infant is delivered, crying, and apparently unharmed. As the nurses towel dry the infant, I rub my right hand ruefully, smiling, thinking that my hand will be sore for a while. The fear that I had worked to suppress during the preceding minutes fades.

This article was externally peer reviewed.

Submitted 17 November 2014; revised 19 January 2015; accepted 26 January 2015.

From the Department of Family and Preventive Medicine, The University of Utah School of Medicine, Salt Lake City.

Funding: none.

Conflict of interest: none declared.

Corresponding author: Osman Sanyer, MD, Department of Family and Preventive Medicine, The University of Utah School of Medicine, 375 Chipeta Way, Suite A, Salt Lake City, UT 84108 (E-mail: osman.sanyer@hsc.utah.edu).
In the 3 decades that have passed since I attended my first delivery as a medical student, the number of my family physician colleagues who deliver babies has dwindled. I have continued to deliver babies for both personal and practical reasons. During my years practicing with the community health center, maternity care was a service that was essential to the underserved and uninsured populations whom we served. I attended between 100 and 120 deliveries each year. In the context of a busy outpatient family medicine practice, this volume of deliveries was frequently exhausting. After I joined a university faculty family medicine practice, I continued to provide maternity care, albeit at a slower pace. This choice to continue was in part due to necessity, as family medicine residency programs are required to train residents to deliver babies despite a diminishing proportion of family physicians who choose to include maternity care in their practices. In addition, I had developed a growing appreciation for the enrichment this aspect of my practice was bringing to my life. And, in truth, I took pride in being a family physician who "still did OB." This was a significant part of my professional identity. In recent years it has been a gift to deliver the babies of the now young adults whose births I attended a couple of decades ago.

I ignored the pain and impairment from my injured hand for several weeks. After an evening of congratulatory hand shaking (and one exuberant "high 5") at our residency graduation ceremony, 
the knuckles on my right hand were again swollen. I was unable to do simple tasks with my dominant hand. I consulted an orthopedic colleague. The surgeon's opinion caught me by surprise; I was not expecting to be told that this seemingly minor injury had resulted in significant ligament damage. It would take months of caution and protection to allow for proper healing. Until that mending was complete, I would not have the capability to effectively and safely deliver infants in complicated situations, those in which both skill and mechanical force might be required. I made the decision to stop delivering babies that day. Given these realities, my faculty colleagues were supportive of my decision.

I am a vivid dreamer. A few months after giving up my maternity practice, I dreamt that I was in a grocery store. I was abruptly called on to deliver a pregnant woman on the floor of the produce section. I woke from the dream surprised to find tears flooding my eyes. I was not prepared for the crushing grief that gripped me as the fading impressions of the dream yielded to wakefulness. I lay in bed with a profound sense of loss, an emptiness. With the arrival of full consciousness, the grief passed. I have not forgotten this moment.

Meaning is different from happiness. In fact, the events and aspects of our lives that provide meaning are often sources of great discomfort and unhappiness. But this meaning is essential in providing context and a richness to our human existence. My maternity practice gave me a chance to reflect on the immediate mismatch between happiness and meaning, particularly during those births that occurred at 3 o'clock in the morning. The disruption of those predawn hours spent waiting on the labor floor offered a quiet space, a chance to consider the hope and uncertainty that accompany the entry of a human life into our world, as well as a moment to consider the cumulative events and choices in my own life that placed me at that birth event. My dream, the tears, were an acknowledgment, a tribute to the gift made up of those cumulative moments of meaning. And with this acknowledgment came an understanding that a part of what has been my life, is no longer.

Five months after I stopped providing maternity care, I am sitting in a room with a patient. The two of us have shared a 3-year running dialogue about the harm being caused by his daily alcohol consumption. My voiced concerns are always acknowledged with courtesy, but no willingness to change. His wife and children, while physically safe, have given up on altering his daily drinking pattern. $\mathrm{He}$ has talked of a pervasive sense of loneliness. This day, he comes to my office with his wife. He has completely lost control of his drinking. He is shaking visibly, and his eyes are dark, almost empty, with a hint of sadness and fear. His last drink was 3 hours earlier. It is now 9 o'clock in the morning. $\mathrm{He}$ is ready to stop drinking. His wife watches and listens, sitting quietly to the side, her face a mix of apprehension and relief. Phone calls are made, he agrees to go to the hospital to start treatment. As we shake hands at the end of the visit, he looks me in the eye for the first time that day. The handshake is held for an instant that is just perceptibly longer than is typical. I turn away and walk to the door of the next examination room. I pause. I am blinking back tears, the first tears that I can recall since awakening from my dream about the grocery store birth.

I intend to keep practicing as a family physician for years to come, perhaps decades. In the months since I stopped delivering babies, I have realized that, as family physicians, we are all participants in the "birthing" process. For some of us, this includes the physical practice of delivering babies. For the rest of us it is more existential, a practice of assisting our patients, over time, through the losses and the damage that are inherent parts of most lives. The gestational period is often far longer than 9 months. In an intimacy that approximates that of a physical birth, we may observe and assist as our patients are first "pregnant" or "prenascent" with thoughts of change, then labor greatly (sometimes for years) through physical and emotional injuries, and finally, often amazingly and against all odds, deliver themselves on to a new life that follows. The hopes and fears associated with these journeys strike me in their similarity to those accompanying the birth of an infant. If we are attentive, and when we choose to stay present, we have the opportunity to recognize meaning, a professional and personal gift that is always associated with the event of a birth. 